\title{
Using Tallquist Haemoglobin Scale for Estimating Intraoperative Blood Loss in Liposuction
}

\author{
Ahmed Abdelmoez Alsayed \\ Independent Researcher, Al-Hokail, Khobar, KSA \\ Email: az971986@gmail.com
}

How to cite this paper: Alsayed, A.A. (2020) Using Tallquist Haemoglobin Scale for Estimating Intraoperative Blood Loss in Liposuction. Modern Plastic Surgery, 10, 17-22.

https://doi.org/10.4236/mps.2020.102003

Received: March 5, 2020

Accepted: March 29, 2020

Published: April 1, 2020

Copyright $\odot 2020$ by author(s) and Scientific Research Publishing Inc. This work is licensed under the Creative Commons Attribution International License (CC BY 4.0).

http://creativecommons.org/licenses/by/4.0/

\section{(c) (i) Open Access}

\begin{abstract}
Introduction: Intraoperative blood loss remains as a concern for all surgeons. Proper estimation of intraoperative blood loss is critical and can be challenging, especially if the blood is mixed with other fluids such as tumescent fluid in liposuction cases. In such cases, proper estimation of intraoperative blood loss will lead to fewer mistakes in fluid resuscitation. In this article, Tallquist Haemoglobin Scale was tried to estimate intraoperative blood loss in liposuction. Objectives: Proper estimation of intraoperative blood loss in liposuction cases. Method: Tallquist Haemoglobin Scale will be tried to estimate the approximate intraoperative blood loss in liposuction cases using a mathematical formula that considers total fluid loss, patient's preoperative haemoglobin and the reading from Tallquist kit. Results: Tallquist Haemoglobin Scale can be considered as a valid method for proper estimation of intraoperative blood loss in liposuction cases, the thing that will lead to correct fluid resuscitation and fewer complications. Conclusion: Proper estimation of intraoperative blood loss leads to fewer mistakes in fluid resuscitation and fewer related complications of under or overcorrection. Tallquist Haemoglobin scale is a trusted, cheap and fast method for proper estimation of intraoperative blood loss in liposuction cases.
\end{abstract}

\section{Keywords}

Tallquist, Haemoglobin, Scale, Blood Loss, Super Wet, Liposuction, Tumescent, Fluid, Resuscitation

\section{Introduction}

Intraoperative blood loss remains as a concern for all surgeons. Proper estimation of intraoperative blood loss is critical and can be challenging, especially if 
the blood is mixed with other fluids such as tumescent fluid in liposuction cases. In such cases, proper estimation of intraoperative blood loss will lead to fewer mistakes in fluid resuscitation and protecting patients from under or over fluid balance correction.

To understand fluid balance in liposuction cases, two definitions should be covered:

1) Intraoperative fluid ratio 8: defined as the volume of super-wet solution and intraoperative intravenous fluid divided by the aspiration volume.

Trott et al., stated that it should be 2.1 for small-volume (aspirate $<4000 \mathrm{cc}$ ) and 1.4 for large-volume (aspirate $>4000 \mathrm{cc}$ ) [1].

Rohrich et al., revised the ratio to be 1.8 for the small-volume reductions (aspirate $<5000 \mathrm{cc}$ ) and 1.2 for the large-volume reductions (aspirate $>5000 \mathrm{cc}$ ) [2].

2) Final residual fluid volume: all intakes and outputs should be meticulously measured as follows: residual fluid volume $=($ total fluid volume in $)-($ total volume out); total fluid volume in = (total fluid volume of wetting solution used $)+$ (total volume of IV fluid used) + (volume of bupivacaine/steroid solution); and total volume out $=$ [total volume of aspirated wetting solution (which is approximately $30 \%$ of the total aspirated volume in most cases)] + urine output [3].

The average residual volume by Wang et al. [3] was around $110 \mathrm{~mL} / \mathrm{kg}$, and was $120 \mathrm{~mL} / \mathrm{kg}$ in the report of Commons et al. [4].

IV fluid infused intraoperatively should equal:

1) Fasting deficit: hourly maintenance ${ }^{\star}$ number of fasting hours.

2) Hourly maintenance: body weight $+40 \mathrm{ml} /$ hour.

3) Estimated fluid loss from surgical trauma: $4-6 \mathrm{~mL} / \mathrm{kg} / \mathrm{hr}$. (liposuction was considered as a moderate surgical trauma) [5].

In 1996, Trott et al. suggested guidelines for intraoperative fluid resuscitation. Patients having less than $4000 \mathrm{cc}$ of lipoaspirate removed received maintenance fluid only, whereas those having more than $4000 \mathrm{cc}$ of lipoaspirate removed received maintenance plus $0.25 \mathrm{cc}$ of intravenous fluid for each milliliter aspirated over $4000 \mathrm{cc}$ [1].

To limit the degree of fluid overloading and possibility of pulmonary edema, Rohrich et al. modified the replacement fluid delivery at $0.25 \mathrm{cc}$ of intravenous fluid for each milliliter aspirated over $5000 \mathrm{cc}$ [2].

Although blood loss in super wet liposuction is supposed to be $1 \%$ of the aspirate [6], it is possible to exceed that percentage in some occasions e.g. technical issues, coagulopathy, etc. I recommend replacing the estimated blood loss with colloids in 1:1 ratio [7], unless one of the blood transfusion indications is met.

As a fast review of blood transfusion indications, World Health Organization (WHO) defined them, in adults, as one of the following:

1) Perioperative transfusion: $8 \mathrm{~g} / \mathrm{dL}$ for patient undergoing major surgery or experiencing GIT bleeding. 
2) Acute blood loss: $30 \%$ of volume of blood.

considering that One unit of whole blood/packed red blood cells can increase haemoglobin by $1 \mathrm{~g} / \mathrm{dL}$ in an adult or haematocrit by $3 \%$ (haemoglobin of unit must be $>75 \%$ ) [8].

National Institute for Health and Care Excellence (NICE) guidelines mention that when using a restrictive red blood cell transfusion threshold, consider a threshold of $70 \mathrm{~g} /$ liter and a haemoglobin concentration target of $70-90 \mathrm{~g} /$ liter after transfusion.

Restrictive red blood cell transfusion thresholds are for patients who need red blood cell transfusions and who do not:

- have major haemorrhage or

- have acute coronary syndrome or

- need regular blood transfusions for chronic anaemia [9].

In literature, several methods of estimating haemoglobin can be found. Direct cyanmethaemoglobin method has been the gold standard for haemoglobin estimation but other methods like haemoglobin color scale, Sahli technique, Lovibond-Drabkin technique, Tallquist technique, copper-sulfate method, HemoCue and automated haematology analyzers are also available [10].

In my opinion, two points had to be considered before choosing the haemoglobin estimation method:

1) The method should be manual, simple, fast without need for power supply.

2) The method should be able to detect very low concentrations of haemoglobin as we are trying to estimate the fraction/percentage of blood in a fluid not to estimate haemoglobin concentration in a proper blood sample.

For both of the considerations above, digital devices are not the best choice for the task. I chose Tallquist haemoglobin scale as a method (Figure 1).

The use of the Tallquist method in assessing anemia is of, relatively, high validity and diagnostic accuracy. Tallquist method should be an effective method to detect mild to moderate anemia in a reliable manner comparable to other standard methods such as the haematocrit and haemoglobin cyanide methods [12].

\section{Methods}

1) After finishing liposuction, super wet in our case, the aspirated fluid volume $\left(\mathrm{V}_{\mathrm{F}}\right)$ is to be calculated, $400 \mathrm{cc}$ in our example here (Figure 2).

2) Take a drop of the aspirated fluid and apply it on one filter paper, comes with Tallquist kit, wait till glistening disappears and compare it, before it completely dries, with the different color grades on the scale. The closest in our example was $4.7 \mathrm{~g} / \mathrm{dl}$ (fluid haemoglobin concentration) $\left(\mathrm{Hb}_{\mathrm{F}}\right)$ (Figure 3). Percentages on the scale indicate the ratio of the sample haemoglobin to a standardized sample of $15.6 \mathrm{~g} / \mathrm{dl}$ haemoglobin. Do not use percentages in calculations not to get mixed with Hematocrit values.

3) Go back to the patient's preoperative investigations and get the haemoglobin value $\left(\mathrm{Hb}_{\mathrm{P}}\right)$ (Table 1$)(13.6 \mathrm{~g} / \mathrm{dl}$ in our case). 


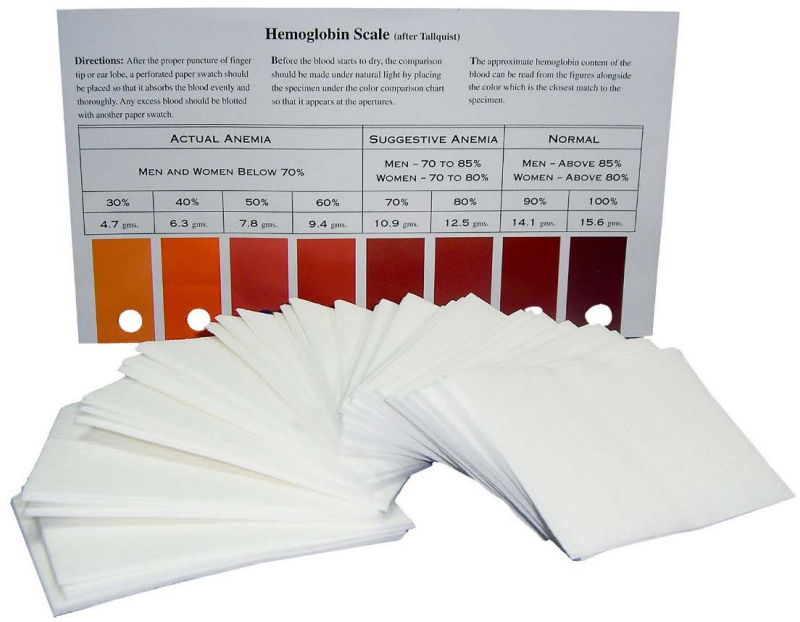

Figure 1. Tallquist haemoglobin scale [11].

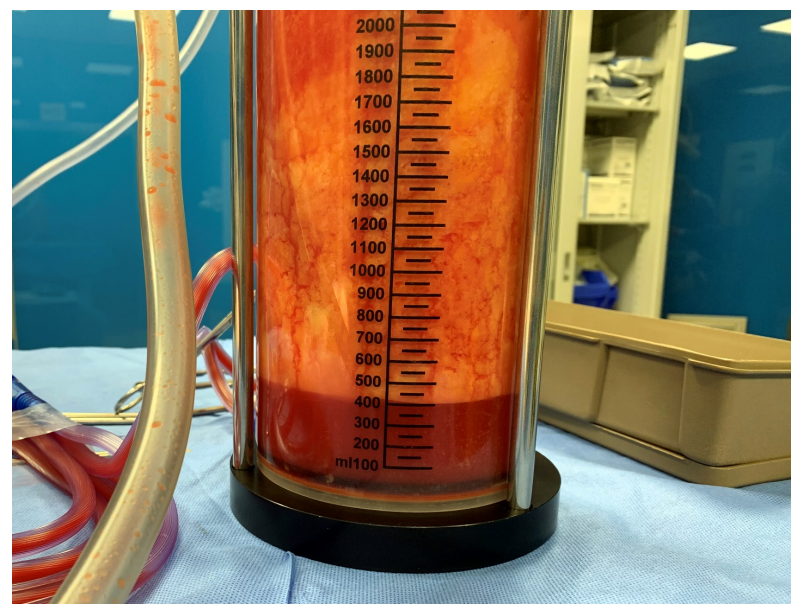

Figure 2. The aspirated fluid volume $\left(\mathrm{V}_{\mathrm{F}}\right)(400 \mathrm{cc}$ in our example).

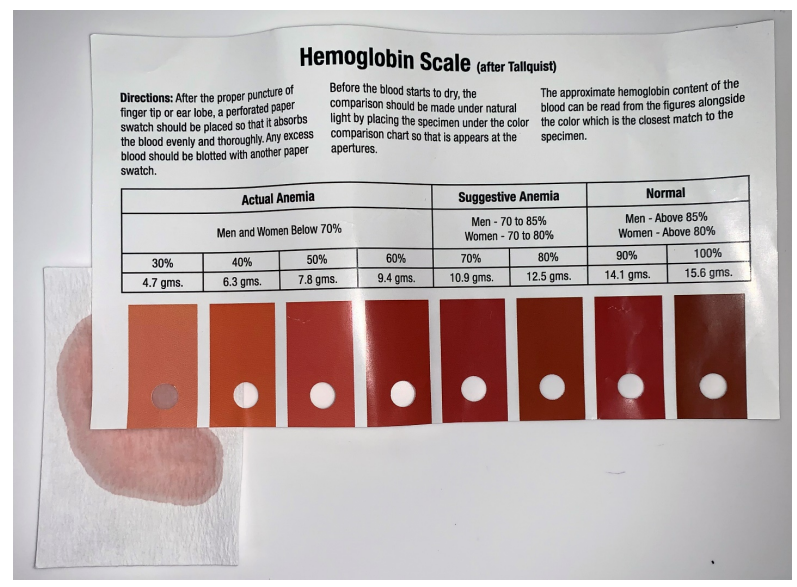

Figure 3. Take a drop of the aspirated fluid and apply it on one filter paper, comes with Tallquist kit, wait till glistening disappears and compare it, before it completely dries, with the different color grades on the scale. The closest in our example was $4.7 \mathrm{~g} / \mathrm{dl}\left(\mathrm{Hb}_{\mathrm{F}}\right)$. 
Table 1. Example patient's preoperative investigations: Haemoglobin concentration $\left(\mathrm{Hb}_{\mathrm{P}}\right)$.

\begin{tabular}{cccc}
\hline \multicolumn{4}{c}{ Complete Blood Count $(\mathrm{CBC})$} \\
\hline Test & Result & Unit & Reference Range \\
Haemoglobin $(\mathrm{Hb})$ & 13.6 & $\mathrm{~g} / \mathrm{dl}$ & $12.0-15.0$ \\
\hline
\end{tabular}

4) Calculate the volume of intraoperative blood loss $\left(V_{L}\right)$ through applying the classic concentration/volume formula $(\mathrm{C} 1 \mathrm{~V} 1=\mathrm{C} 2 \mathrm{~V} 2)$

$$
\begin{aligned}
& \text { Preoperativepatient's haemoglibin concentration }(\mathrm{HbP}) \\
& \times \text { Volume of intraoperative blood loss }(\mathrm{VL}) \\
& =\text { Aspirated fluid haemoglobin concentration }(\mathrm{HbF}), \\
& \times \text { Volume of Total aspirated fluid }(\mathrm{VF})
\end{aligned}
$$

and as a result,

$$
\mathrm{V}_{\mathrm{L}}=\mathrm{Hb}_{\mathrm{F}} * \mathrm{~V}_{\mathrm{F}} / \mathrm{Hb}_{\mathrm{P}}=4.7 * 400 / 13.6=138 \mathrm{cc}
$$

\section{Results}

Tallquist Haemoglobin Scale can be considered as a valid method for proper estimation of intraoperative blood loss in liposuction cases using a mathematical formula that considers total fluid loss, patient's preoperative haemoglobin and the reading from Tallquist kit, the thing that will lead to correct fluid resuscitation and fewer complications.

\section{Discussion and Conclusion}

Proper estimation of intraoperative blood loss will lead to fewer mistakes in fluid resuscitation, using crystalloids, colloids or blood, and protecting patients from under or over fluid balance correction. Application of the mentioned method can be expanded to be used in other surgeries with further blood loss. Tallquist Haemoglobin Scale can be considered as a valid method for proper estimation of intraoperative blood loss in liposuction cases. A classic mathematical formula that addresses volume and concentration of both pure patient's blood and the aspirated fluid can be applied to detect the approximate intraoperative blood loss. Blood loss from the postoperative oozing should be considered as a next target for analysis.

\section{Data Availability}

The author confirms that the data supporting the findings of this study are available within the article.

\section{Conflicts of Interest}

The author declares no conflicts of interest regarding the publication of this paper. 


\section{References}

[1] Trott, S.A., Beran, S.J., Rohrich, R.J., Kenkel, J.M., Adams Jr., W.P. and Klein, K.W. (1998) Safety Considerations and Fluid Resuscitation in Liposuction. An Analysis of 53 Consecutive Patients. Plastic and Reconstructive Surgery, 102, 2220-2229. https://doi.org/10.1097/00006534-199811000-00063

[2] Rohrich, R., Leedy, J., Swamy, R., Brown, S.A. and Coleman, J. (2006) Fluid Resuscitation in Liposuction: A Retrospective Review of 89 Consecutive Patients. Plastic and Reconstructive Surgery, 117, 431-435. https://doi.org/10.1097/01.prs.0000201477.30002.ce

[3] Wang, G., Cao, W. and Zhao, T. (2018) Fluid Management in Extensive Liposuction. Medicine, 97, e12655. https://doi.org/10.1097/MD.0000000000012655

[4] Commons, G.W., Halperin, B. and Chang, C.C. (2001) Large-Volume Liposuction: A Review of 631 Consecutive Cases over 12 Years. Plastic and Reconstructive Surgery, 108, 1753-1763. https://doi.org/10.1097/00006534-200111000-00051

[5] Intraoperative Fluid Dosing in Adult Patients-MDCalc. https://www.mdcalc.com/intraoperative-fluid-dosing-adult-patients\#evidence

[6] Granados-Tinajero, S., Buenrostro-Vásquez, C., Cárdenas-Maytorena, C. and Contreras-López, M. (2019) Anesthesia Management for Large-Volume Liposuction. Anesthesia Topics for Plastic and Reconstructive Surgery, 4, 71-90. https://doi.org/10.5772/intechopen.83630

[7] Broadstone, R. (1999) Fluid Therapy and Newer Blood Products. Veterinary Clinics of North America: Small Animal Practice, 29, 611-628. https://doi.org/10.1016/S0195-5616(99)50051-X

[8] World Health Organization (2020) Clinical Transfusion Practice Guidelines for Medical Interns.

https://www.who.int/bloodsafety/transfusion_services/ClinicalTransfusionPractice GuidelinesforMedicalInternsBangladesh.pdf

[9] NICE (2015) Blood Transfusion, NICE Guideline [NG24], Guidance: Recommendations: Red Blood Cells: Thresholds and Targets (1.2.2). National Institute for Health and Care Excellence (NICE).

[10] Srivastava, T., Negandhi, H., Neogi, S.B., Sharma, J. and Saxena, R. (2014) Methods for Haemoglobin Estimation: A Review of "What Works". Journal of Hematology \& Transfusion, 2, 1028 .

[11] Stemfinity.com. (2020). Tallquist Haemoglobin Scale. Kemtec Science. STEMfinity. https://www.stemfinity.com/Kemtec-Science-Tallquist-Haemoglobin-Scale

[12] Wasiu Olalekan, A. and Olufemi Emmanuel, A. (2016) How Valid Is the Tallquist Method in Screening Pregnant Women with Anemia in Poor Rural Settings of Southwestern Nigeria? Medical Journal of the Islamic Republic of Iran, 30, 389. 